\title{
Screening of Cardiovascular Autonomic Neuropathy in Patients with Diabetes by Quick and Simple Assessment of Sudomotor Function
}

\section{Calvet $\mathrm{JH}^{1 *}$, Dupin $\mathrm{J}^{1}$ and Deslypere JP2}

${ }^{1}$ Impeto Medical, Paris, France

${ }^{2}$ Aesculape, Singapore

\begin{abstract}
Aims: Cardiovascular Autonomic Neuropathy (CAN) is a common but overlooked complication of diabetes Sympathetic C-fibers innervating sweat glands can be impaired early in patients with diabetes. SUDOSCAN, a new and non-invasive device that assesses sudomotor function, was compared to Heart Rate Variability (HRV) and to Ewing tests, known to be reliable methods for the investigation of CAN.

Methods: 232 patients with diabetes were measured for HRV at rest and during moderate activity (stai climbing). Time and frequency domain analysis techniques, including measurement of Standard Deviation of the average NN intervals over 5 minutes (SDNN), High Frequency domain component (HF) and Low Frequency domain component (LF), were assessed during HRV testing. Heart rate variations during deep breathing and heart rate and blood pressure responses while standing, as described by Ewing were also assessed. Electrochemical Sweat Conductance (ESC) was measured on the hands and feet, and a risk score was calculated. Patients were classified according to their risk score. The classifications were as follow: no sweat dysfunction, moderate sweat dysfunction and high sweat dysfunction. All results are means \pm SD.

Results: The highest correlation was observed between the risk score based on sudomotor function and the LF component during moderate activity $(r=0.47, p<0.001)$. The risk score was higher in patients with a LF component value during moderate activity of $<90 \mathrm{~ms}^{2}$ ( $1^{\text {st }}$ quartile) when compared to LF $>405 \mathrm{~ms}^{2}$ ( $3^{\text {rd }}$ quartile) (46 \pm 13 vs 30 $\pm 13, \mathrm{p}<0.001)$. When taking the LF power component during moderate activity $<90 \mathrm{~ms}^{2}$ as a reference value, the AUC of the ROC curve for the SUDOSCAN risk score was 0.77 .

Conclusions: SUDOSCAN allowing quick and quantitative assessment of sudomotor function can be used for the early screening of cardiovascular autonomic neuropathy in daily clinical practice before more sophisticated, specific, and time-consuming tests.
\end{abstract}

Keywords: Sudomotor function; Heart rate variability; Ewing tests; Cardiovascular autonomic neuropathy

\section{Introduction}

Peripheral neuropathy is the most prevalent complication of type 2 diabetes [1]. Autonomic neuropathy is probably the most overlooked area in the field of neuropathy [2]. Cardiovascular Autonomic Neuropathy (CAN) has been shown to be the most important risk factor for silent ischemia in patients with diabetes [3]. Heart Rate Variability (HRV) with time and frequency domain analysis is a non-invasive and objective method to assess sympathetic and parasympathetic modulation of the heart rate. It is generally accepted that the sympathetic system modulates the Low Frequency (LF) component whereas the parasympathetic system controls the High Frequency (HF) component [4]. Exercise has been shown to increase the accuracy of HRV analysis [5]. A joint consensus statement of the American Diabetes Association (ADA) and the American Academy of Neurology recommended that a battery of Cardiovascular Autonomic Reflex Tests (CARTs) assessing HRV during deep breathing or standing and monitoring postural systolic blood pressure fall (usually described as Ewing tests) should be performed to assess CAN [6,7].

Sweat glands are innervated by thin and unmyelinated sympathetic C-fibers that can be impaired by peripheral neuropathy, dependent upon their length. Sudomotor dysfunction has been evidenced in prediabetes and diabetes, and a consensus statement of the ADA suggests that sudomotor function should be included in the diagnostic test for the early detection of neuropathies in diabetes [8]. Several methods have been developed, but the lack of easy and quick tests to diagnose sudomotor dysfunction has restricted widespread use in clinical practice [9]. SUDOSCAN is a new device for quick, non-invasive and quantitative assessment of sudomotor function [10]. Several studies have shown that SUDOSCAN could be used to screen sympathetic system dysfunction in patients with Impaired Glucose Tolerance (IGT) or diabetes [11-13].

The aim of this study was to compare SUDOSCAN findings with HRV at rest and during moderate exercise, along with CARTs, in patients with type 2 diabetes.

\section{Materials and Methods}

Patients attending Diabetes Clinic with type 2 diabetes between 21 75 years of age with or without peripheral or cardiac neuropathy were enrolled in the study after informed consent was signed.

Exclusion criteria were: patients taking drugs that would have an ef-

*Corresponding author: Calvet $\mathrm{JH}$, Impeto Medical, 17 rue Campagne Première, 75014, Paris, France, Tel: +33143201640; Fax: +33143351833; E-mail: jean-henri.calvet@impeto-medical.com

Received April 13, 2011; Accepted May 18, 2012; Published May 23, 2012

Citation: Calvet JH, Dupin J, Deslypere JP (2012) Screening of Cardiovascular Autonomic Neuropathy in Patients with Diabetes by Quick and Simple Assessment of Sudomotor Function. J Diabetes Metab 3:192. doi:10.4172/2155-6156.1000192

Copyright: $\odot 2012$ Calvet JH, et al. This is an open-access article distributed under the terms of the Creative Commons Attribution License, which permits unrestricted use, distribution, and reproduction in any medium, provided the original author and source are credited. 
fect on the sympathetic system, such as beta blocker or anti-arrhythmic drugs; amputation of arms or legs; patients suffering from either seizures or epilepsy; and patients having suffered Myocardial Infarction (MI) and/or stroke in the past 6 months.

\section{Heart rate variability}

Cardiac autonomic function was evaluated by heart rate variability analysis on a 3 lead ECG recording patients at rest (15 min) and during moderate activity (stair climbing at moderate speed, $45 \mathrm{~min}$ ). The Holter ECG recordings were analyzed on a commercially available Holter analysis system at a sampling rate of $200 \mathrm{~Hz}$ using a certified program (SyneScope, ELA Medical, France). Only R-R intervals between successive normal beats (normal to normal R-R) were included in the calculation of HRV. Recordings with greater than $1 \%$ ectopy or excessive artifacts were excluded from analysis. Time domain analysis was performed with the calculation of Standard Deviation of Normal to Normal R-R intervals (SDNN) correlated to total autonomic activity, and Root Mean Squared of Successive Differences (RMSSD) correlated to parasympathetic activity. Frequency domain analysis was based on Fast Fourier Transform (FFT) with Total Power (TP); Very Low Frequency (VLF: < 0.040 Hz); Low Frequency (LF: 0.04-0.15 Hz), mainly mediated by the sympathetic system; and High Frequency (HF: 0.15-0.40 $\mathrm{Hz}$ ), mainly mediated by parasympathetic system. Power components were expressed in absolute units $\left(\mathrm{ms}^{2}\right)$. The LF/HF ratio, considered as an index of cardiovascular sympathetic/parasympathetic tone balance, was also calculated.

\section{Cardiac Autonomic Reflex Tests (CARTs)}

The International Diabetes Foundation (IDF) has recommended the use of resting heart rate and heart rate response to provocation tests (lying/standing, Valsalva, deep breathing) in addition to lying/standing blood pressure difference for the diagnosis of CAN [4]. The ADA has recommended only orthostatic hypotension and resting tachycardia for the diagnosis of CAN [14]. We used orthostatic hypotension and two tests based on ECG to diagnose CAN. Each test was carried out according to the standard procedure described by Ewing et al. [4] using a commercial ECG system (CANS, Chennai, India). The CARTs testing procedures are as follows:

ECG during deep breathing (E:I Ratio): R-R intervals during inhalation and exhalation are calculated. The longest R-R interval is determined during expiration ( $\mathrm{R}-\mathrm{R} \max$ ) and the shortest interval during inspiration (R-R min). The ratio of the longest to shortest $\mathrm{R}-\mathrm{R}$ interval is called the E:I ratio. Normal values are $>1.21$.

ECG to standing (30:15 Ratio): The shortest R-R interval is measured after standing, which is around the $15^{\text {th }}$ beat. This is followed by bradycardia, which is indicated by the longest $\mathrm{R}-\mathrm{R}$ interval around the $30^{\text {th }}$ beat. The ratio of the longest to shortest R-R interval is calculated, which is called 30:15 ratio. Normal values are $>1.03$.

Blood pressure response to standing (Orthostatic Blood Pressure Response): The postural fall in blood pressure is measured as the difference between the systolic blood pressure lying and standing. Normal fall for systolic blood pressure is $<20 \mathrm{mmHg}$.

\section{Measurement of sweat function}

SUDOSCAN is a patented device designed to perform a precise evaluation of sweat gland function based on an electrochemical reaction between sweat chloride and nickel electrodes on which a low Direct Current (DC) is applied and has been described previously [10-13]. It's a dynamic method based on stimulation of sweat glands by the low- level voltage, allowing evidence of sweat dysfuntion not detectable in physiological conditions. The device consists of two sets of electrodes for the feet and hands which are connected to a computer for recording and data management. This is a non-invasive test and requires two minutes, during which four combinations of 15 different low DC voltages are applied. No subject preparation is required for this test. The subject places the palms of the hands and the soles of the feet on the electrodes. The device measures the Electrochemical Sweat Conductance (ESC) of the hands and feet (right and left sides) using the ratio of the current measured over the constant power applied, expressed in microSiemens $(\mu \mathrm{S})$. A risk score for CAN is calculated from these conductances and additional biometric data (age and BMI): no risk $(\leq 25)$, moderate risk (]25-50]) and high risk scores (> 50). These threshold values were issued from previous clinical studies.

Results for quantitative variables are shown as means \pm SD. Log transformation was undertaken for outcome variables not normally distributed (RMSSD, TP, VLF, LF and HF). Quantitative variables were globally compared using a Student's t test. Percentages were compared using a Fischer exact test. Analysis of variance (ANCOVA) and logistic regression, adjusted for diabetes duration, Body Mass Index (BMI) and gender, have been performed to compare quantitative variables and percentages. As a rule, a p-value $<0.05$ was regarded as statistically

\begin{tabular}{|c|c|c|}
\hline & Coefficient of correlation & P- value \\
\hline LF at moderate activity & 0.47 & $<0.001$ \\
\hline HF at moderate activity & 0.40 & $<0.001$ \\
\hline $\begin{array}{c}\text { Total power at moderate } \\
\text { activity }\end{array}$ & 0.38 & $<0.001$ \\
\hline CART, 30:15 ratio & 0.36 & $<0.001$ \\
\hline VLF at moderate activity & 0.34 & $<0.001$ \\
\hline LF at rest & 0.34 & $<0.001$ \\
\hline Total power at rest & 0.33 & $<0.001$ \\
\hline RMSSD at moderate activity & 0.32 & $<0.001$ \\
\hline VLF at rest & 0.30 & $<0.001$ \\
\hline SD at rest & 0.28 & $<0.001$ \\
\hline HF at rest & 0.27 & $<0.001$ \\
\hline RMSSD at rest & 0.23 & $<0.001$ \\
\hline
\end{tabular}

Table 1: Spearman's rank correlation coefficient of SUDOSCAN risk score with HRV components and CARTs data.

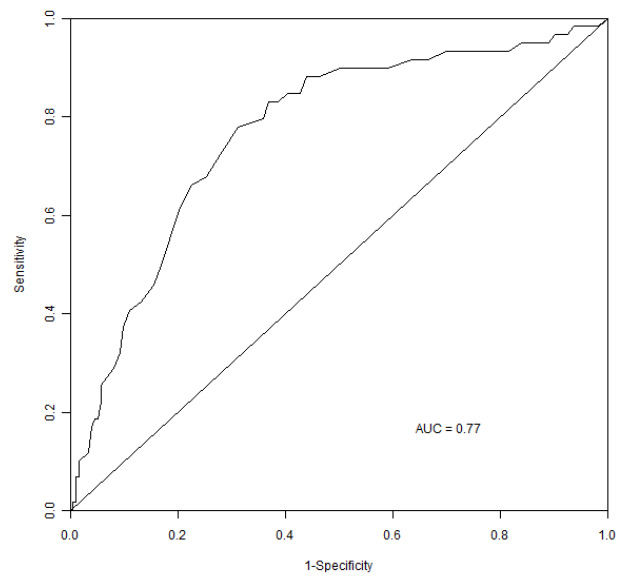

Figure 1:Graphic representation of the diagnostic performance of SUDOSCAN risk score, by Receiver Operating Curve (ROC) analysis when choosing LF power component value during moderate activity $<90 \mathrm{~ms}^{2}$ ( $1^{\text {st }}$ quartile) as reference value. With a risk score cut-off point of $<40 \%$ (optimal Youden index), sensitivity was $83 \%$, specificity was $63 \%$ and the Youden index was 0.46 


\begin{tabular}{|c|c|c|c|c|c|c|}
\hline & \multirow[b]{3}{*}{ All } & \multicolumn{3}{|c|}{ LF at moderate activity } & \multirow[b]{3}{*}{ P-value } & \multirow[b]{3}{*}{ P-value adjusted* } \\
\hline & & Below than 1st quartile & Interquartile range & $\begin{array}{l}\text { Higher than } 3 \text { rd } \\
\text { quartile }\end{array}$ & & \\
\hline & & $<90 \mathrm{~ms}^{2}$ & ]90-405] $\mathrm{ms}^{2}$ & $>405 \mathrm{~ms}^{2}$ & & \\
\hline $\mathrm{N}$ & 232 & 58 & 116 & 58 & & \\
\hline Men participants & $140(60 \%)$ & $25(43 \%)$ & $74(64 \%)$ & $41(71 \%)$ & 0.006 & - \\
\hline Diabetes duration (years) & $9 \pm 7$ & $12 \pm 7$ & $9 \pm 7$ & $6 \pm 6$ & $<0.001$ & - \\
\hline BMI $\left(\mathrm{kg} / \mathrm{m}^{2}\right)$ & $26 \pm 4$ & $28 \pm 4$ & $26 \pm 3$ & $25 \pm 3$ & $<0.001$ & - \\
\hline Age (years) & $52 \pm 9$ & $56 \pm 9$ & $53 \pm 8$ & $48 \pm 11$ & $<0.001$ & - \\
\hline $\mathrm{HbA}_{1 \mathrm{C}}(\%)$ & $8.5 \pm 1.8$ & $9.3 \pm 2.0$ & $8.2 \pm 1.6$ & $8.2 \pm 1.6$ & $<0.001$ & 0.005 \\
\hline $\mathrm{HR}$ at rest (bpm) & $78 \pm 11$ & $86 \pm 10$ & $76 \pm 10$ & $72 \pm 9$ & $<0.001$ & $<0.001$ \\
\hline $\mathrm{SBP}(\mathrm{mmHg})$ & $120 \pm 16$ & $128 \pm 15$ & $119 \pm 16$ & $114 \pm 14$ & $<0.001$ & 0.001 \\
\hline $\mathrm{DBP}(\mathrm{mmHg})$ & $76 \pm 8$ & $79 \pm 8$ & $76 \pm 9$ & $74 \pm 7$ & $<0.001$ & 0.011 \\
\hline ESC hands $(\mu S)$ & $59 \pm 20$ & $55 \pm 21$ & $59 \pm 19$ & $61 \pm 21$ & NS & NS \\
\hline ESC feet $(\mu S)$ & $59 \pm 21$ & $52 \pm 24$ & $59 \pm 19$ & $66 \pm 19$ & 0.002 & 0.054 \\
\hline SUDOSCAN risk score & $37 \pm 15$ & $46 \pm 13$ & $37 \pm 13$ & $30 \pm 13$ & $<0.001$ & $<0.001$ \\
\hline Abnormal E:I ratio $(<1.21)$ & $46(20 \%)$ & $23(40 \%)$ & $20(17 \%)$ & $3(5 \%)$ & $<0.001$ & $<0.001$ \\
\hline $\begin{array}{c}\text { Abnormal 30:15 ratio } \\
(<1.03)\end{array}$ & $71(31 \%)$ & $33(57 \%)$ & $34(29 \%)$ & $4(7 \%)$ & $<0.001$ & $<0.001$ \\
\hline $\begin{array}{l}\text { Orthostatic hypotension } \\
\qquad(>20 \mathrm{mmHg})\end{array}$ & $17(7 \%)$ & $7(12 \%)$ & $8(7 \%)$ & $2(3 \%)$ & NS & NS \\
\hline
\end{tabular}

Data are means \pm SD

${ }^{*} \mathrm{P}$-value adjusted on gender, diabetes duration and BMI

Table 2: Demographic and SUDOSCAN characteristics according to LF values at moderate activity.

significant. Spearman's rank correlation coefficient was calculated. The data management and statistical analysis were done using SAS version 9.3 and $\mathrm{R}$ version 2.13.1[14].

\section{Results}

Table 1 gives the correlation between CAN risk score as assessed by SUDOSCAN and various HRV and CARTs parameters. As the highest correlation was observed with the LF component at moderate activity $(\mathrm{r}=0.47, \mathrm{p}<0.001)$, which reflects mainly sympathetic activity, patients were classified according to this parameter. Table 2 indicates main patient characteristics, main results for CARTs and main SUDOSCAN data according to LF component values during moderate activity. Patients are classified in values below the $1^{\text {st }}$ quartile, in interquartile range, and higher than the $3^{\text {rd }}$ quartile. As a significant difference was observed in gender, BMI, and diabetes duration, analysis was adjusted based on these 3 parameters. Table 3 indicates main patient characteristics, main parameters of HRV, and main results of CARTs according to SUDOSCAN risk score, with patients classified using no risk $(\leq 25)$, moderate risk (]25-50]) and high risk scores (> 50). Figure provides graphic representation of the diagnostic performance of SUDOSCAN risk scores, analyzed by Receiver Operating Curve (ROC) analysis when choosing LF component value $<90 \mathrm{~ms}^{2}$ during moderate activity $\left(1^{\text {st }}\right.$ quartile) as the reference value. When choosing a risk score cut-off point of $40 \%$ (optimal Youden index), sensitivity was $83 \%$, specificity was $63 \%$ and the Youden index was 0.46 .

No adverse events or discomfort during and after measurement were reported.

\section{Discussion}

This study shows that there is a good correlation between the risk score issued from the assessment of sweat function and HRV, especially the LF component at moderate activity and the 30:15 ratio of CART.

CAN is a common chronic complication of diabetes with important clinical and prognostic relevance [3]. Autonomic innervation is the primary extrinsic control regulating HRV and cardiac performance. Clinical symptoms of autonomic dysfunction may not appear until long after the onset of diabetes, and there is no widely accepted single approach for the diagnosis of CAN in diabetes [2]. However, subclinical CAN, manifested as changes in HRV, may be detected earlier. Additionally, HRV has been shown to be a strong, independent predictor of mortality after acute myocardial infarction [3]. Studies on HRV measurements are generally performed on 24-hour ECG recordings to get information regarding rest and activity periods, with time and frequency domain analysis performed to allow exploration of sympathetic and parasympathetic components. However, these studies cannot be performed on a large scale. Recordings of patients over short periods either resting supine or at various levels of activity improves the accuracy of the method, in particular the sympathetic component, which is increased during exercise while there is a withdrawal of parasympathetic activity [5].

The highest correlation of SUDOSCAN risk scores is observed with the LF power component during moderate activity, which is linked to the sympathetic component as well as sweat function. A lower correlation was observed with the LF power component at rest, compared to moderate activity ( 0.36 vs 0.47$)$. Quartiles were chosen as threshold values for classification based on LF power component as it is difficult to find reference values in literature especially for LF power component during moderate activity. Similarly, a significant difference was observed for the LF power component during moderate activity when patients were classified according to SUDOSCAN risk score, while no significant difference was observed for LF at rest when adjusted based on BMI, diabetes duration, and gender. This could be explained by the fact that moderate activity increases sympathetic activity, and thus the LF power component [5].

CARTs have been proposed for the diagnosis of CAN, but they are very time consuming and consequently are not performed in daily practice [6,7]. In addition, one CART test is based on the Valsalva manoeuvre and cannot be performed on some patients for safety reasons. 
Citation: Calvet JH, Dupin J, Deslypere JP (2012) Screening of Cardiovascular Autonomic Neuropathy in Patients with Diabetes by Quick and Simple Assessment of Sudomotor Function. J Diabetes Metab 3:192. doi:10.4172/2155-6156.1000192

Page 4 of 5

\begin{tabular}{|c|c|c|c|c|c|c|}
\hline & \multirow[b]{2}{*}{ All } & \multicolumn{3}{|c|}{ SUDOSCAN risk score } & \multirow[b]{2}{*}{ P-value } & \multirow[b]{2}{*}{ P-value adjusted* } \\
\hline & & Risk score $\leq 25$ & Risk score [25-50] & Risk score $>50$ & & \\
\hline $\mathrm{N}$ & 232 & 44 & 149 & 39 & & \\
\hline Men participants & $140(60 \%)$ & $31(70 \%)$ & $90(60 \%)$ & $19(49 \%)$ & 0.130 & - \\
\hline Diabetes duration (years) & $9 \pm 7$ & $4 \pm 4$ & $9 \pm 6$ & $15 \pm 7$ & $<0.001$ & - \\
\hline $\operatorname{BMI}\left(\mathrm{kg} / \mathrm{m}^{2}\right)$ & $26 \pm 4$ & $24 \pm 3$ & $26 \pm 3$ & $29 \pm 4$ & $<0.001$ & - \\
\hline Age (years) & $52 \pm 9$ & $44 \pm 8$ & $53 \pm 8$ & $59 \pm 7$ & $<0.001$ & - \\
\hline $\mathrm{HbA}_{1 \mathrm{C}}(\%)$ & $8.5 \pm 1.8$ & $7.4 \pm 1.8$ & $8.3 \pm 1.5$ & $10.3 \pm 1.7$ & $<0.001$ & $<0.001$ \\
\hline $\mathrm{SBP}(\mathrm{mmHg})$ & $120 \pm 16$ & $117 \pm 16$ & $119 \pm 16$ & $127 \pm 16$ & 0.011 & NS \\
\hline $\mathrm{DBP}(\mathrm{mmHg})$ & $76 \pm 8$ & $77 \pm 10$ & $76 \pm 8$ & $77 \pm 7$ & NS & NS \\
\hline ESC hands $(\mu S)$ & $59 \pm 20$ & $72 \pm 18$ & $58 \pm 19$ & $46 \pm 18$ & $<0.001$ & $<0.001$ \\
\hline ESC feet $(\mu S)$ & $59 \pm 21$ & $77 \pm 10$ & $58 \pm 19$ & $43 \pm 20$ & $<0.001$ & $<0.001$ \\
\hline \multicolumn{7}{|l|}{$\mathrm{HR}$ variability at rest } \\
\hline Heart Rate (bpm) & $78 \pm 11$ & $77 \pm 11$ & $77 \pm 11$ & $81 \pm 11$ & NS & NS \\
\hline SDNN (ms) & $35 \pm 18$ & $39 \pm 18$ & $36 \pm 18$ & $28 \pm 18$ & 0.001 & NS \\
\hline RMSSD (ms) & $24 \pm 20$ & $28 \pm 26$ & $24 \pm 18$ & $20 \pm 21$ & 0.044 & NS \\
\hline $\mathrm{TP}\left(\mathrm{ms}^{2}\right)$ & $1353 \pm 1410$ & $1688 \pm 1447$ & $1385 \pm 1428$ & $851 \pm 1168$ & $<0.001$ & 0.036 \\
\hline $\operatorname{VLF}\left(\mathrm{ms}^{2}\right)$ & $699 \pm 752$ & $915 \pm 849$ & $701 \pm 751$ & $442 \pm 549$ & $<0.001$ & 0.098 \\
\hline $\operatorname{LF}\left(\mathrm{ms}^{2}\right)$ & $355 \pm 423$ & $392 \pm 317$ & $384 \pm 470$ & $200.0 \pm 285$ & $<0.001$ & 0.079 \\
\hline $\mathrm{HF}\left(\mathrm{ms}^{2}\right)$ & $221 \pm 371$ & $260 \pm 442$ & $228 \pm 359$ & $148 \pm 322$ & 0.002 & 0.047 \\
\hline $\mathrm{LF} / \mathrm{HF}$ & $2.8 \pm 2.3$ & $3.1 \pm 2.3$ & $2.7 \pm 2.2$ & $2.9 \pm 2.4$ & NS & NS \\
\hline \multicolumn{7}{|l|}{ HR variability during moderate activity } \\
\hline Heart Rate (bpm) & $93 \pm 11$ & $92 \pm 12$ & $92 \pm 11$ & $97 \pm 10$ & 0.017 & NS \\
\hline SDNN (ms) & $70 \pm 27$ & $76 \pm 27$ & $69 \pm 27$ & $66 \pm 24$ & NS & NS \\
\hline RMSSD (ms) & $20 \pm 16$ & $24 \pm 18$ & $19 \pm 12$ & $19 \pm 25$ & 0.020 & NS \\
\hline $\mathrm{TP}\left(\mathrm{ms}^{2}\right)$ & $1477 \pm 1373$ & $2059 \pm 1591$ & $1444 \pm 1336$ & $942 \pm 975$ & $<0.001$ & NS \\
\hline $\operatorname{VLF}\left(\mathrm{ms}^{2}\right)$ & $964 \pm 932$ & $1300 \pm 997$ & $957 \pm 943$ & $611 \pm 657$ & $<0.001$ & NS \\
\hline $\operatorname{LF}\left(\mathrm{ms}^{2}\right)$ & $295 \pm 299$ & $449 \pm 325$ & $289 \pm 299$ & $142 \pm 162$ & $<0.001$ & 0.019 \\
\hline $\mathrm{HF}\left(\mathrm{ms}^{2}\right)$ & $107 \pm 228$ & $172 \pm 415$ & $104 \pm 166$ & $45 \pm 74$ & $<0.001$ & 0.034 \\
\hline LF/HF & $4.8 \pm 3.1$ & $5.2 \pm 3.1$ & $4.6 \pm 3.1$ & $4.9 \pm 3.2$ & NS & NS \\
\hline \multicolumn{7}{|l|}{ CARTs } \\
\hline Abnormal E:I ratio $(<1.21)$ & $46(20 \%)$ & $6(14 \%)$ & $26(17 \%)$ & $14(36 \%)$ & 0.027 & 0.028 \\
\hline Abnormal $30: 15$ ratio $(<1.03)$ & $71(31 \%)$ & $5(11 \%)$ & $44(30 \%)$ & $22(56 \%)$ & $<0.001$ & $<0.001$ \\
\hline Orthostatic hypotension (> $20 \mathrm{mmHg}$ ) & $17(7 \%)$ & $3(7 \%)$ & $10(7 \%)$ & $4(10 \%)$ & NS & NS \\
\hline
\end{tabular}

Data are means \pm SD

${ }^{*} \mathrm{P}$-value adjusted on gender, diabetes duration and BMI

Table 3: Demographic, HRV and CARTs characteristics according to SUDOSCAN risk score values.

Thus, in order to have the same tests performed for all patients; this test was excluded from this study.

Thin and unmyelinated small nervous fibers can be damaged very early in the development of diabetes, dependent upon length. Small fiber neuropathy has been proposed as a marker of peripheral neuropathy in diabetes [8]. Since sweat glands are innervated by small sympathetic C-fibers, the assessment of sudomotor function has been suggested to assess peripheral autonomic neuropathy, especially in patients with diabetes [9]. The gold standard for sudomotor function assessment is QSART $[9,15]$. However, this method lacks a simple, quick, non-invasive approach, which has not allowed for its use on a large scale. Lesions in the peripheral autonomic and cardiac autonomic nervous systems should theoretically progress in parallel. Itoh et al. observed a correlation between orthostatic hypotension and sweat dysfunction as assessed by QSART, which is in the range of the correlation found in the present study between the 30:15 ratio and the SUDOSCAN risk score $(\mathrm{r}=0.51$, $\mathrm{p}=0.001$ and $\mathrm{r}=0.36, \mathrm{p}<0.001$ respectively) [16]. According to the results of this study (which must be confirmed in a larger population) SUDOSCAN-a simple, non-invasive, quick and quantitative methodcould be used as a screening test for cardiovascular autonomic neu- ropathy before more specific, specialized, and time-consuming tests. It would allow for better management of patients with type 2 diabetes and help in avoiding the development and progression of life-threatening complications.

\section{References}

1. Boulton JM, Malik RA, Arezzo JC, Bril V, Feldman EL, et al. (2005) Diabetic neuropathies: A statement by the American Diabetes Association. Diabetes Care 28: 956-962.

2. Vinik AI, Maser RE, Mitchell BD, Freeman R (2003) Diabetic autonomic neuropathy. Diabetes Care 26: 1553-1579.

3. Tesfaye S, Chaturvedi N, Eaton SE, Ward JD, Manes C, et al. (2005) Vascular risk factors and diabetic neuropathy. $\mathrm{N}$ Engl J Med 352: 341-350.

4. Ewing DJ, Martyn CN, Young RJ, Clarke BF (1985) The value of cardiovascular autonomic function tests: 10 years experience in diabetes. Diabetes Care 8 491-498.

5. Freeman JV, Dewey FE, Hadley DM, Myers J, Froelicher VF (2006) Autonomic nervous system interaction with the cardiovascular system during exercise. Prog Cardiovasc Dis 48: 342-362.

6. (1988) Report and recommendation of the San Antonio Conference on diabetic neuropathy. Consensus statement. Diabetes 37: 1000-1004. 
Citation: Calvet JH, Dupin J, Deslypere JP (2012) Screening of Cardiovascular Autonomic Neuropathy in Patients with Diabetes by Quick and Simple Assessment of Sudomotor Function. J Diabetes Metab 3:192. doi:10.4172/2155-6156.1000192

Page 5 of 5

7. Akselrod S, Gordon D, Ubel FA, Shannon DC, Berger AC, et al. (1981) Power spectrum analysis of heart rate fluctuation: a quantitative probe of beat-to-beat cardiovascular control. Science 213: 220-222.

8. Tesfaye S, Boulton AJ, Dyck PJ, Freeman R, Horowitz M, et al. (2010) Diabetic neuropathies: update on definition, diagnostic criteria, estimation of severity and treatments. Diabetes Care 33: 2285-2293.

9. Low PA (2004) Evaluation of sudomotor function. Clin Neurophysiol 115: $1506-$ 1513.

10. Mayaudon $\mathrm{H}$, Miloche PO, Bauduceau B (2010) A new simple method to assessing sudomotor function: relevance in type 2 diabetes. Diabetes Metab 36: 450-454

11. Gin H, Baudouin R, Raffaitin C, Rigalleau V, Gonzalez C (2011) Non invasive and quantitative assessment of sudomotor function for peripheral diabetic neuropathy evaluation. Diabetes Metab 37: 527-532.
12. Ramachandran A, Moses A, Shetty S, Thirupurasundari CJ, Seeli AC, et al. (2010) A new non-invasive technology to screen for dysglycemia including diabetes. Diabetes Res Clin Pract 88: 302-306.

13. Schwarz PEH, Brunswick P, Calvet JH (2011) EZSCAN a new technology to detect diabetes risk. British Journal of Diabetes and Vascular Diseases 11: 204-209.

14. The R Project for Statistical Computing

15. Provitera V, Nolano M, Caporaso G, Stancanelli A, Santoro L, et al. (2010) Evaluation of sudomotor function in diabetes using the dynamic sweat test. Neurology 74: 50-56.

16. Itoh H, Uebori S, Asai M, Kashiwaya T, Atoh K, et al. (2003) Early Detection of Orthostatic Hypotension by Quantitative Sudomotor Axon Reflex Test (QSART) in Type 2 Diabetic Patients. Intern Med 42: 560-564. 